Egyptian

Orthodontic Journal

\title{
MAXILLARY SYMMETRY, MANDIBULAR SYMMETRY AND CONDYLAR POSITION IN FUNCTIONAL UNILATERAL POSTERIOR CROSS BITE PATIENTS
}

\author{
Ahmed M. Madian'1, Nadia M. El-Harouni², \\ Essam M. Abdallah² \\ ABSTRACT: \\ Objective: To investigate mandibular symmetry, maxillary \\ symmetry and condylar position in patients with functional \\ unilateral posterior crossbite (FUPXB) using Multi-slice computed \\ tomography (MSCT). Materials and Methods: 15 patients (mean \\ age $13 \pm 3$ years) with FUPXB underwent MSCT scans. Skeletal \\ and dental measurements were taken to assess mandibular and \\ maxillary symmetry. Medial and Lateral Joint spaces were \\ compared between normal and crossbite sides in those patients. \\ Results: There were no statistically significant differences \\ between crossbite and normal sides regarding skeletal and dental \\ mandibular and maxillary measurements and regarding condylar \\ position. Conclusions: patients with FUPXB showed mandibular \\ and maxillary symmetry. Those patients revealed symmetric \\ condylar position between normal and crossbite sides.
}

\section{INTRODUCTION}

Posterior crossbite is not an uncommon type of malocclusion as it has a prevalence of $7 \%$ to $23 \%$ among malocclusions in the deciduous and mixed dentitions ${ }^{(1-9)}$. Posterior crossbite can involve 1 tooth or a group of teeth, It can be either unilateral or bilateral and either have a skeletal or

1- Assistant Lecturer, Department of Orthodontics, Faculty of Dentistry, Alexandria University.

2- Professor, Department of Orthodontics, Faculty of Dentistry, Alexandria University. 
Egyptian

Orthodontic Journal

dento-alveolar origin ${ }^{(10)}$. The most common form of posterior crossbite is a unilateral presentation, with a functional shift of the mandible toward the crossbite $\operatorname{side}^{(11)}$. This is known as functional unilateral posterior crossbite (FUPXB) ${ }^{(10)}$. The association between FUPXB and asymmetrical condyle position within the glenoid fossa is a subject of continuous debate and also the presence of an asymmetric condyle position within the glenoid fossa met interest in the literature. Some suggested that FUPXB may result in right to left side differences in the condyle fossa relationships which results in tempero-mandibular joint (TMJ) disc displacement and internal derangement ${ }^{(12)}$.

The development of computerized tomography (CT) has, to some extent, helped to reach the proper investigation of the effect of FUPXB on condyle-fossa relationships with higher accuracy ${ }^{(13,14)}$ to overcome the methodological drawbacks of previous techniques. Our purpose is to test the null hypothesis that: (1) There is no mandibular asymmetry in FUPXB patients. (2) There is no maxillary asymmetry in FUPXB patients. (3) There is no difference in the condylar position between the crossbite and normal sides in FUPXB patients.

\section{MATERIALS AND METHODS}

\section{Subjects:}

15 patients were selected from those attending the department of Orthodontics, Faculty of Dentistry, Alexandria University. [the number of patients was determined according to the equation using the Larry Connors method].Patients included were selected by having Functional Unilateral Posterior Crossbite (FUPXB) which was diagnosed by a crossbite on one side only (unilateral), mandibular midline was shifted toward the crossbite side at the maximum intercuspal position and not in the $\mathrm{m}$ outh opening. The mandibular midline shift was $2 \pm 1 \mathrm{~mm}$. The Age range was from $10-16$ years. Patients with craniofacial deformities involving condyles and/or mandible or chronic systemic diseases affecting bone or teeth or history of orthodontic treatment were excluded from the study. Full extra-oral and intra-oral examinations were done and a complete set of records including photographs and dental casts were taken. All subjects signed an informed consent before participation in the research and the ethical committee approval was granted to conduct the study. 
Egyptian

Orthodontic Journal

\section{Methods:}

Axial scans with the scan field starting caudally from the lower most aspect of the mandible up to the level of the superior orbital margin so as to include the whole mandible, maxilla, TMJ and orbital bones were obtained using 8 slice GE, lightspeed (General Electric, USA) scanner. with Scan parameters: $200 \mathrm{mAs}, 120 \mathrm{KVP}, 0.6 \mathrm{~s} / \mathrm{rot}, 0.625 \mathrm{~mm}$ slice thickness, zero interval. Patients were instructed to lie in a supine position in maximum dental intercuspation during the examination and not to move during the CT examination. The images were taken in $0.65 \mathrm{~mm}$ thickness and the data were transferred to workstation (GE, advantage 4.4) for manipulation of data with dedicated software for 3D.Reconstructions were then done in both soft and high resolution volumes then sent to the workstations where multiplanner and 3D reconstructions were done using dedicated dental software.

\section{The following measurements were taken:}

(1) Maxillary Measurements: [these measurements were performed on the right and left sides on the coronal cuts to show symmetryl

A. Skeletal Measurements : (fig.1)(this coronal cut was showing the two palatine foraminae) Maxillary width, parallel to the lower border of the hard palate and tangent to the nasal floor, extended from the maxillary alveolar bone to the skeletal midline.

B. Dental Measurements :

- Distance between the most prominent area of the buccal aspect of the first molar tooth and the dental midline.(fig.2)

- Distance between the most prominent area of the buccal aspect of the first premolar tooth and the dental midline.(fig.3)

- Distance between the most prominent area of the palatal aspect of the first molar tooth and the dental midline.(fig.2)

- Distance between the most prominent area of the palatal aspect of the first premolar tooth and the dental midline.(fig.3) 
(2) Mandibular Measurements : [these measurements were performed on the right and left sides to show symmetryl

A. Skeletal Measurements :(these measurements were assessed from 3D MSCT reconstruction images)

- Length of the corpus : distance between the most distal point of the condyle and pogonion.(fig.4)

- Length of the body: distance between the point Gonion and pogonion. (fig.5)

- Intercondylar distance : distance between the most lateral points of the two condyles.(fig.6)

B. Dental Measurements: (these measurements were assessed from the coronal cut)

- Distance between the most prominent area of the buccal aspect of the first premolar and the midline which was a line passing between the symphysis and tubercles.(fig.7)

- Distance between the most prominent area of the lingual aspect of the first premolar and the midline which was a line passing between the symphysis and tubercles.(fig.7)

(3) Measurements of the TMJ : [these measurements were performed on the right and left sides to show symmetryl Coronal cut : (at the level of the maximum width of the condyle)

- Medial Joint Space(MJS): perpendicular distance from the line connecting the most superior area of the fossa and the most medial superior point of the condyle to the medial wall of the glenoid fossa.(fig.8)

- $\quad$ Lateral Joint Space(LJS): perpendicular distance from the line connecting the most superior area of the fossa and the most lateral superior point of the condyle to the lateral wall of the glenoid fossa.(fig.8)

* The measurements were taken by two examiners for interobserver reliability. 


\section{Egyptian \\ Orthodontic Journal}

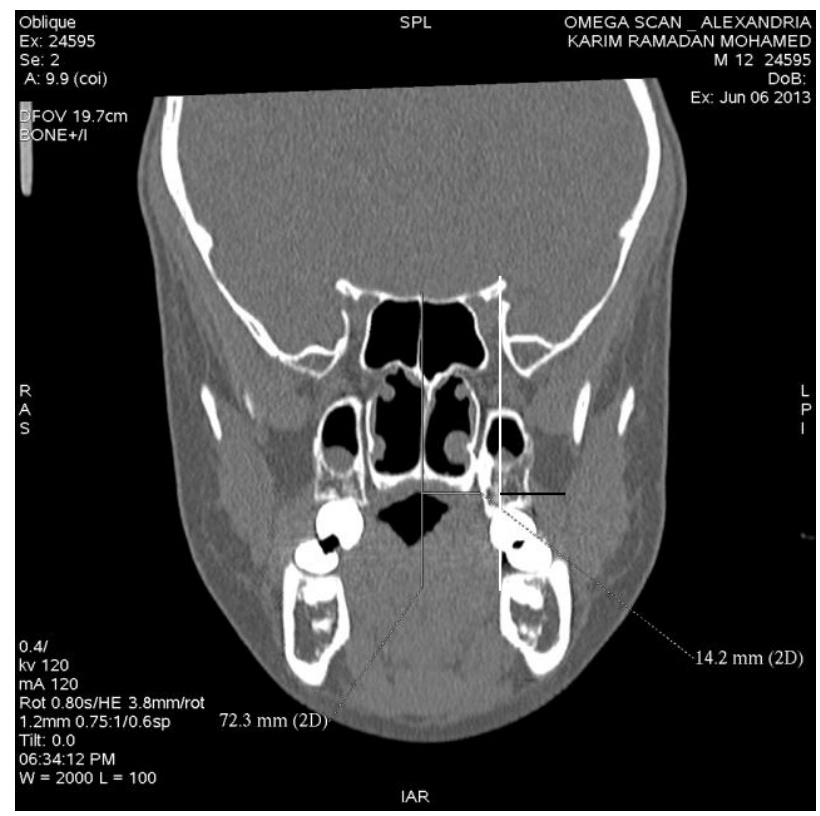

Fig. 1 Skeletal maxillary width

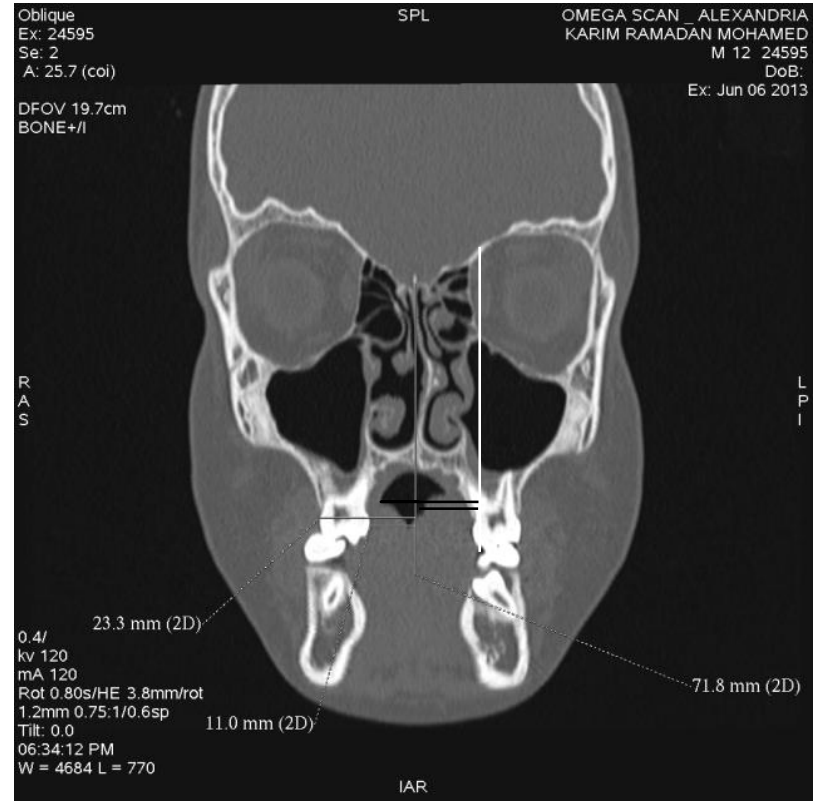

Fig. 2 Maxillary dental measurement at right first molar 


\section{Egyptian \\ Orthodontic Journal}

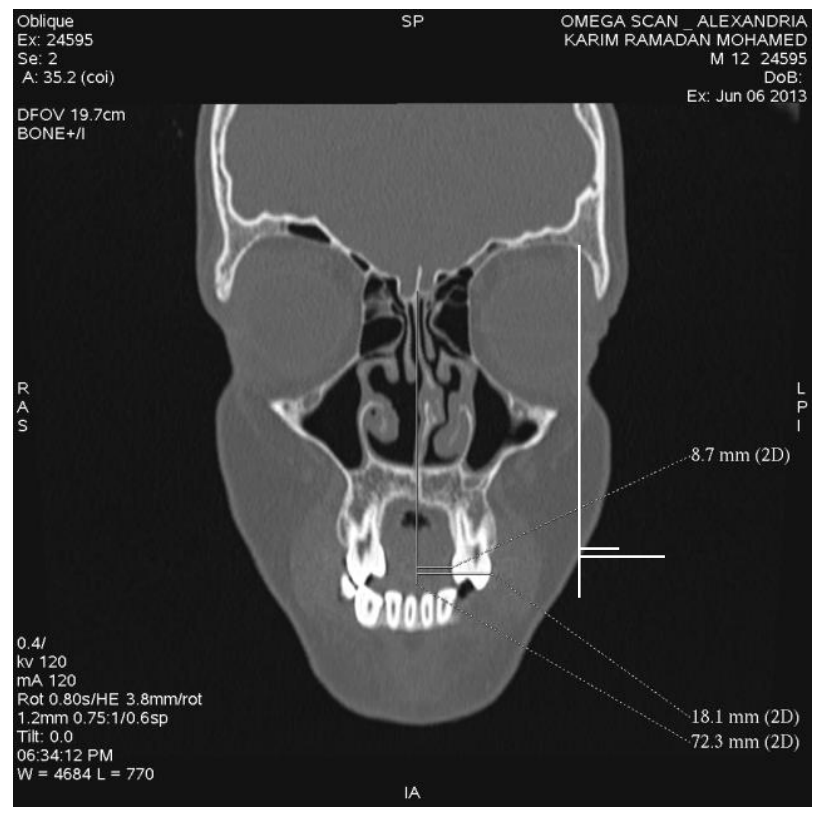

Fig. 3 Maxillary dental measurement at left first premolar

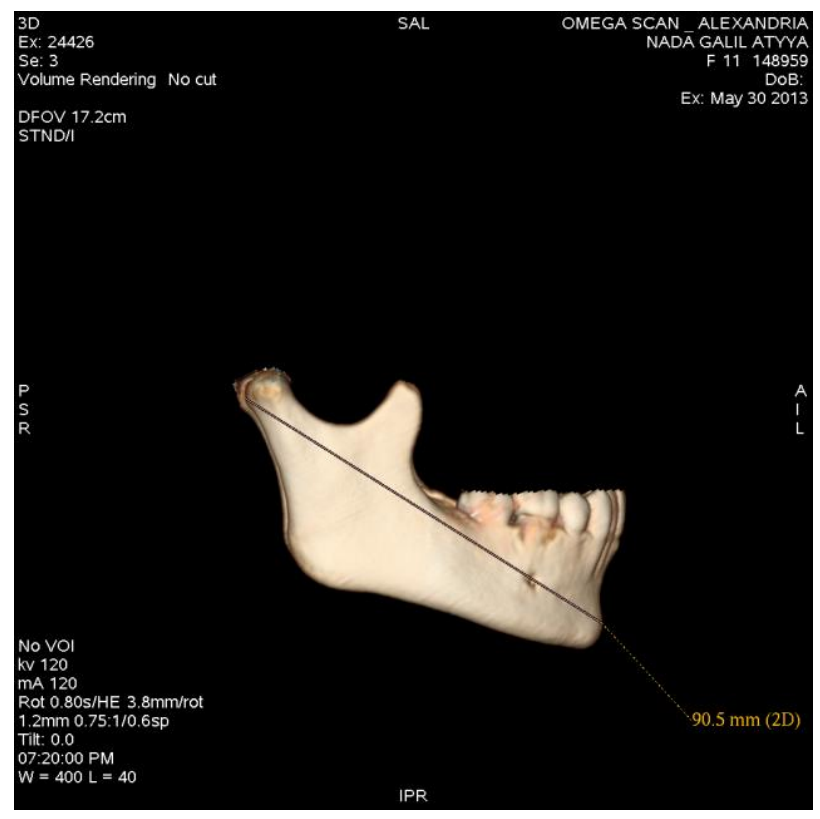

Fig. 4 Length of the corpus 


\section{Egyptian \\ Orthodontic Journal}

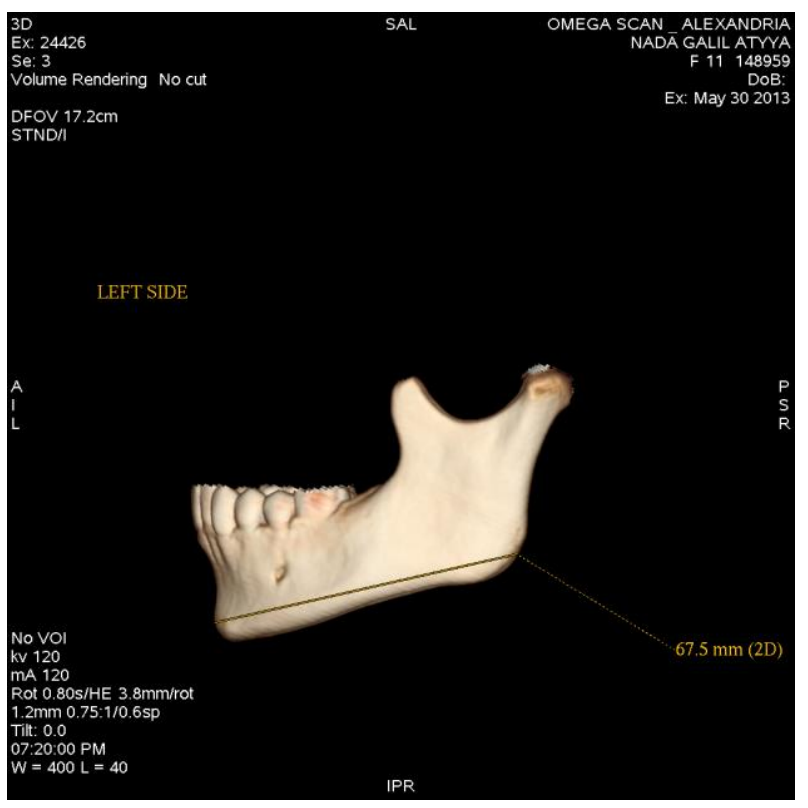

Fig. 5 Length of the body

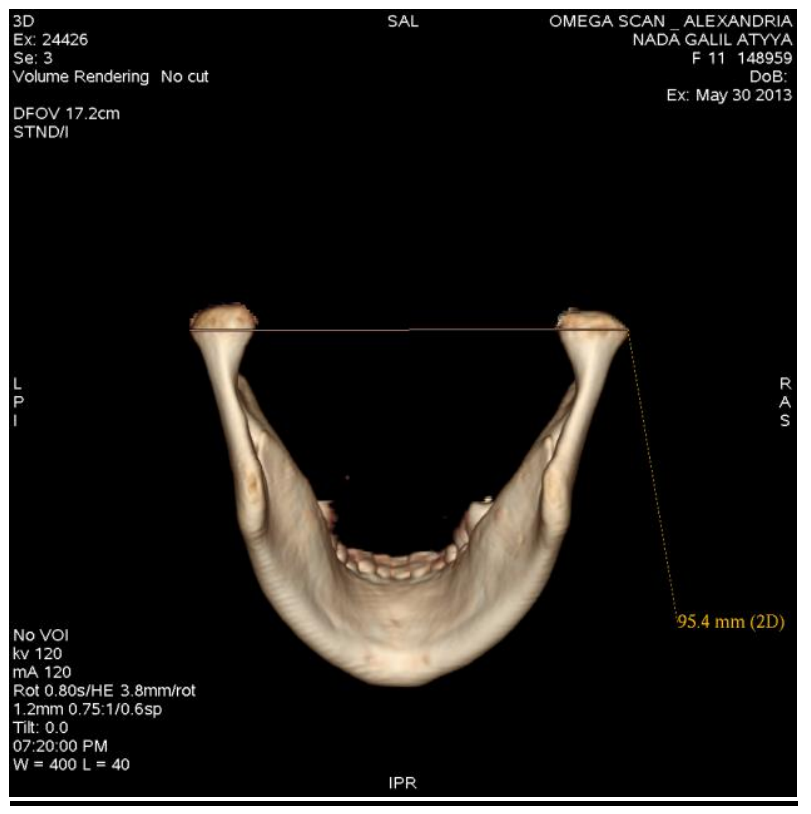

Fig. 6 Intercondylar distance

Volume 48-Decem6er 2015 


\section{Egyptian \\ Orthodontic Journal}

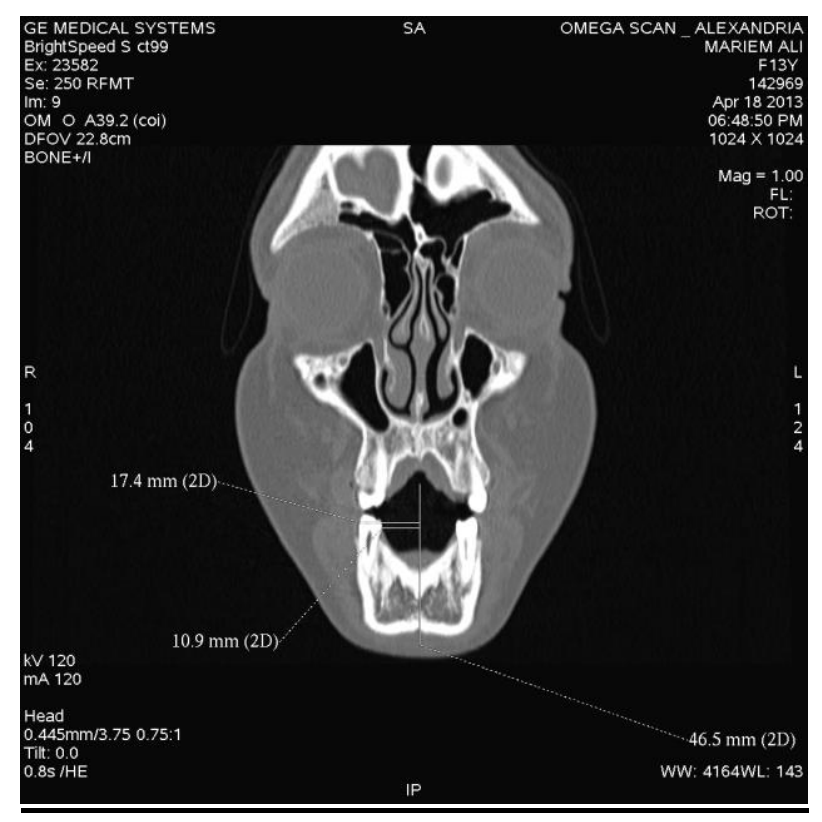

Fig. 7 Mandibular dental measurement at right first premolar

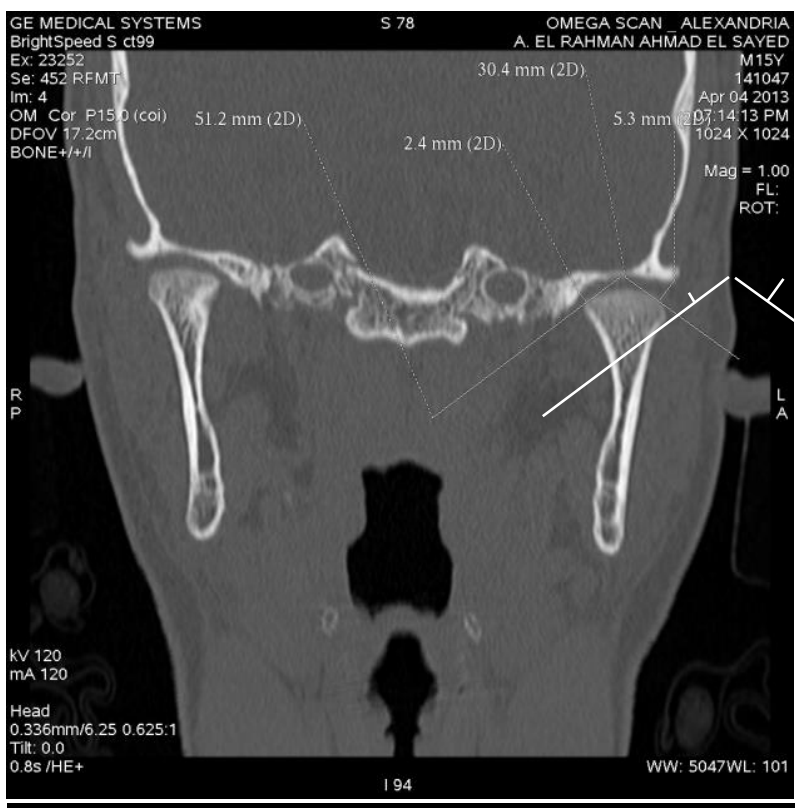

Fig. 8 Medial and lateral Joint Space 
Egyptian

Orthodontic Journal

\section{RESULTS}

Mandibular symmetry (table 1) neither the total length of the mandible nor the mandibular body length showed statistically significant difference between crossbite and normal sides. Dentally, there was also no statistically significant difference between crossbite and normal sides regarding the measurements of the first mandibular premolar to the midline both buccally and lingually. Maxillary symmetry (table 1) The 2 sides, crossbite and normal, elicited no statistically significant difference concerning both skeletal measurements and dental measurements at the first premolar area and first molar area. Condylar position (table 2) Lateral and Medial Joint Spaces showed no statistically significant difference between crossbite and normal sides.

Table (1) Pre-expansion Dental and Skeletal maxillary and mandibular measurements in crossbite and normal sides

\begin{tabular}{|l|c|c|c|}
\hline & Crossbite & Normal & P \\
\hline Mandibular skeletal all mandible & $101.56 \pm 7.39$ & $101.85 \pm 7.41$ & 0.457 \\
Mandibular skeletal mandibular body & $71.33 \pm 7.58$ & $71.37 \pm 6.6$ & 0.494 \\
Mandibular dental (premolar) Buccal & $19.64 \pm 1.65$ & $19.56 \pm 1.52$ & 0.32 \\
Mandibular dental(premolar) Lingual & $12.46 \pm 1.31$ & $12.31 \pm 1.20$ & 0.24 \\
Maxillary skeletal & $15.15 \pm 1.34$ & $14.55 \pm 1.49$ & 0.128 \\
Maxillary dental (premolar) Buccal & $20.45 \pm 2.31$ & $20.4 \pm 1.85$ & 0.345 \\
Maxillary dental (premolar) Palatal & $11.27 \pm 1.812$ & $11.19 \pm 1.944$ & 0.28 \\
Maxillary dental (molar) Buccal & $25.46 \pm 2.569$ & $26.63 \pm 1.9$ & 0.241 \\
Maxillary dental (molar) Palatal & $14.15 \pm 2.497$ & $15.21 \pm 1.76$ & 0.105 \\
\hline
\end{tabular}

Table (2) Pre-expansion measurements of joint spaces in crossbite and normal sides

\begin{tabular}{|l|l|l|c|}
\hline & \multicolumn{1}{|c|}{ Crossbite } & \multicolumn{1}{|c|}{ Normal } & P \\
\hline & & & \\
Lateral joint space & $2.43 \pm 1.22$ & $2.5 \pm 0.83$ & 0.424 \\
Medial joint space & $2.09 \pm 0.70$ & $1.87 \pm 0.37$ & 0.152 \\
\hline
\end{tabular}

Volume 48-December 2015 
Egyptian

Orthodontic Journal

\section{DISCUSSION}

Mandibular symmetry several authors have attempted to find a relationship between mandibular asymmetry and crossbite ${ }^{15}$. In this study, no statistically significant differences were found between crossbite and non crossbite sides regarding the total length of the mandible nor the mandibular body. The dental arches at the molar and premolar area were also found to be symmetrical on both sides. Several studies $^{(16,17)}$ agreed with the current study while others ${ }^{(10,16,18,19)}$ elicited different results. These differences may be either due to the fact that they used submental vertex $(2 \mathrm{D})^{(10,16)}$, Panoramic x.ray ${ }^{18}$ or carrying out the study on different age range ${ }^{16}$ or small sample size ${ }^{19}$. Maxillary symmetry in the present study, no statistically significant differences were found between crossbite and non crossbite sides regarding skeletal and dental maxillary measurements. Kecik et $\mathrm{al}^{10}$ disagreed with the present results finding different dental measurements between crossbite and normal sides. Condylar position It must be stated that on going through literature, the present study was the first to measure medial and lateral joint spaces from the coronal view using MSCT, where they were found to be symmetrical on both sides.

\section{CONCLUSIONS}

Patients with FUPXB are characterized by a symmetric condylar position and symmetric maxillary and mandibular skeletal and dental measurements.

\section{REFERENCES}

1. Borzabadi-Farahani A, Eslamipour F. Malocclusion and occlusal traits in an urban Iranian population: an epidemi-ological study of 11- to 14-year-old children. Eur J Orthod 2009;31:477-84.

2. Da Silva Filho OG, Santamaria M Jr, Capelozza Filho L. Epidemiology of posterior crossbite in the primary dentition. J Clin Pediatr Dent 2007;32:73-8. 
3. Poveda Roda R, Bagan JV, Diaz Fernandez JM, Hernandez, Bazan S, Jimenez Soriano Y. Review of temporo-mandibular joint pathology. Part I: classification, epidemiology and risk factors. Med Oral Patol Oral Cir Bucal 2007;12:E292-E8.

4. Scavone H Jr, Ferreira RI, Mendes TE, Ferreira FV. Prevalence of posterior crossbite among pacifier users: a study in the deciduous dentition. Braz Oral Res 2007;21:153-8.

5. daCosta OO, Orenuga OO. Dentofacial anomalies related to the digit sucking habit. Afr J Med MedSci 2002;31:239-42.

6. Thilander B, Pena L, Infante C, Parada SS, de Mayorga C. Prevalence of malocclusion and orthodontic treatment need in children and adolescents in Bogota, Colombia: an epidemiological study related to different stages of dental development. Eur J Orthod 2001;23:153-67.

7. Sonnesen L, Bakke M, Solow B. Malocclusion traits and symptoms and signs of temporomandibular disorders in children with severe malocclusion. Eur J Orthod 1998;20: 543-59.

8. Brin I, Ben-Bassat Y, Blustein Y, Ehrlich J, Hochman N, Marmary Y, et al. Skeletal and functional effects of treatment for unilateral posterior cross-bite. Am J Orthod Dentofacial Orthop 1996;109:173-9.

9. Keeling SD, McGorray S, Wheeler TT, King GJ. Risk factors associated with temporomandibular joint sounds in children 6 to 12 years of age. Am J Orthod Dentofacial Orthop 1994;105:279-87.

10. Kecik D, Kocadereli I, Saatci I. Evaluation of the treatment changes of functional posterior crossbite in the mixed dentition. Am J Orthod Dentofacial Orthop 2007;131:202-15.

11. Kennedy DB, Osepchook M. Unilateral posterior crossbite with mandibular shift: a review. J Can Dent Assoc 2005;71:569-73.

12. Egermark I, Magnusson T, Carlsson GE. A 20-year follow up of signs and symptoms of temporomandibular disorders and malocclusions in subjects with and without orthodontic treatment in childhood. Angle Orthod 2003;73:109-15. 
Egyptian

Orthodontic Journal

13. Ikeda K, Kawamura A. Assessment of optimal condylar position with limited cone-beam computed tomography. Am J Orthod Dentofacial Orthop 2009;135:495-501.

14. Rodrigues AF, Fraga MR, Vitral RW. Computed tomography evaluation of the temporomandibular joint in Class II Division 1 and Class III malocclusio patients: condylar symmetry and condyle-fossa relationship. Am J Orthod Dentofacial Orthop 2009;136:199-206.

15. Pinto A, Buschang P, Throckmorton G, Chen P. Morphological and positioned asymmetries of young children with functional unilateral posterior crossbite. Am J Orthod Dentofacial Orthop. 2001;120:513-20.

16. Lam PH, Sadowsky C, Omerza F. Mandibular asymmetry and condylar position in children with unilateral posterior crossbite. Am J Orthod Dentofacial Orthop 1999;115:569-75.

17. Veli I, Uysal T, Ozer T, Ucar FI, Eruz M. Mandibular asymmetry in unilateral and bilateral posterior crossbite patients using cone-beam computed tomography. Angle Orthod. 2011;81(6):966-74.

18. Kilic N, Kiki A, Oktay H. Condylar asymmetry in unilateral posterior crossbite patients. Am J Orthod Dentofacial Orthop 2008;133:382-7.

19. Kumar S, Tajr F, Gnanashanmugam, saravanan, kumar N. Effect of posterior unilateral crossbite on condylar head height. Indian Journal of Multidisciplinary Dentistry. 2011;1;(6):333-337. 